\title{
Validation of an IGF-CTP scoring system for assessing hepatic reserve in egyptian patients with hepatocellular carcinoma
}

\author{
Reham Abdel-Wahabi,6, Samir Shehata ${ }^{6}$, Manal M. Hassan'1, Lianchun Xiao², \\ Ju-Seog Lee ${ }^{3}$, Sheree Cheung ${ }^{1}$, Hoda H. Essa ${ }^{6}$, Hesham M. Hassabo ${ }^{1}$, Ahmed S. \\ Shalaby ${ }^{1}$, Eman Mosad7, Kanwal Raghavi ${ }^{1}$, Asif Rashid ${ }^{4}$, Robert A. Wolff ${ }^{1}$, Jeffrey \\ S. Morris ${ }^{2}$, Hesham M. Amin ${ }^{5,8}$ and Ahmed O. Kaseb ${ }^{1}$ \\ ${ }^{1}$ Department of Gastrointestinal Medical Oncology, The University of Texas MD Anderson Cancer Center, Houston, Texas, \\ USA \\ 2 Department of Biostatistics, The University of Texas MD Anderson Cancer Center, Houston, Texas, USA \\ ${ }^{3}$ Department of Systems Biology, The University of Texas MD Anderson Cancer Center, Houston, Texas, USA \\ 4 Department of Pathology, The University of Texas MD Anderson Cancer Center, Houston, Texas, USA \\ ${ }^{5}$ Department of Hematopathology, The University of Texas MD Anderson Cancer Center, Houston, Texas, USA \\ ${ }^{6}$ Department of Clinical Oncology, Assiut University, Egypt \\ 7 Department of Pathology, Assiut University, Egypt \\ ${ }^{8}$ Graduate School of Biomedical Sciences, Houston, Texas, USA \\ Correspondence to: Ahmed O. Kaseb, email: akaseb@mdanderson.org \\ Keywords: IGF-1, Child-Pugh, validation, liver reserve, hepatocellular carcinoma \\ Received: March 26, $2015 \quad$ Accepted: May 01, $2015 \quad$ Published: May 19, 2015
}

This is an open-access article distributed under the terms of the Creative Commons Attribution License, which permits unrestricted use, distribution, and reproduction in any medium, provided the original author and source are credited.

\section{ABSTRACT}

\section{Background}

The Child-Turcotte-Pugh score (CTP) is the standard tool for hepatic reserve assessment in hepatocellular carcinoma (HCC). Recently, we reported that integrating plasma insulin-like growth factor-1 (IGF-1) level into the CTP score was associated with better patient risk stratification in two U.S. independent cohorts. Our current study aimed to validate the IGF-CTP score in patients who have different demographics and risk factors.

Patients and Methods

We prospectively recruited 100 Egyptian patients and calculated their IGF-CTP score compared to CTP score. C-index was used to compare the prognostic significance of the two scoring systems. Finally, we compared our results with our U.S. cohorts published data.

\section{Results}

IGF-CTP score showed significant better patient stratification compared to CTP score in the international validation cohort. Among CTP class A patients, who usually considered for active treatment and clinical trial enrollment, $32.5 \%$ were reclassified as IGF-CTP class B with significantly shorter OS than patients reclassified as class A with hazard ratio $[\mathrm{HR}]=6.15,95 \%$ confidence interval $[\mathrm{CI}]=2.18-17.37$.

Conclusion

IGF-CTP score showed significantly better patient stratification and survival prediction not only in the U.S. population but also in international validation population, who had different demographics and HCC risk factors. 


\section{INTRODUCTION}

While several hepatocellular carcinoma (HCC) prognostic systems rely on the Child-Turcotte-Pugh (CTP) score to assess the underlying chronic liver disease (CLD) and to predict treatment outcome and overall survival (OS).[1] The original CTP scoring system was modified in 1973 to replace nutritional status with an objective variable, prothrombin time, and began to be used for assessment of life expectancy after ligation of bleeding esophageal varices in cirrhotic patients.[2] Patients classified according to CTP score into A, B, or C. Several trials have concluded that patients with CTP classes B and $\mathrm{C}$ have marked deterioration in hepatic function compared to those with class A. Therefore, typically, only patients with class A are eligible for active treatment.[3, 4]

The CTP score is still the standard tool for assessing the degree of hepatic reserve and predicting OS among cirrhotic and HCC patients.[1, 3, 4] However, the CTP scoring system includes two subjective variables (ascites and encephalopathy), which are difficult to assess as both may be influenced by medications, nutritional status and comorbidities. [5-10] These limitations raise the need for a more objective scoring system for better assessment of prognosis, prediction of survival, and decision-making about suitable treatment. $[11,12]$

Our previous studies[13, 14] showed that the baseline plasma level of insulin-like growth factor-1 (IGF-1) was significantly associated with degree of CLD, HCC characteristics and patients' OS duration. We therefore proposed substituting IGF-1 level for the two subjective parameters of the CTP score, creating the IGFCTP (Kaseb-Morris) score. Recently, we found that the IGF-CTP score was significantly associated with better patient stratification compared to the CTP score in both U.S. training and validation cohorts.[15] The aims of the current study were to prospectively validate the IGF-CTP score in an independent cohort of 100 Egyptian patients and compare the results with the two previous cohorts. This study represents the first international validation of our recently reported IGF-CTP score, in a cohort of patients with different demographics, geographical location, and $\mathrm{HCC}$ risk factors.

\section{RESULTS}

\section{Patient characteristics}

MD Anderson training cohort (USA): $420 \mathrm{HCC}$ patients were enrolled between January 2000 and May 2008. Among those, 310 (73.8\%) had available plasma samples.

MD Anderson prospective validation cohort (USA): 197 HCC patients were enrolled between June 2008 and
September 2011. Among those, 155 (78.7\%) had available plasma samples.

Assiut prospective validation cohort (Egypt): 100 HCC patients were enrolled between April 2012 and September 2013, and all had available plasma samples taken on the day of study enrollment in the clinic.

\section{Comparison between the Egyptian validation cohort and previous cohorts}

The median follow-up times were 8.6 months (95\% $\mathrm{CI}=6.8$ to 14.5 months) for the Egyptian validation cohort, compared to 43.3 months ( $95 \% \mathrm{CI}=41$ to 53.5 months) for the training cohort and 16.5 months $(95 \% \mathrm{CI}=9.67$ to 24.1 months) for the MD Anderson validation cohort.

Table 1 highlights the statistically significant variations in patient characteristics between the three cohort groups. The mean age for Egyptian patients was 56.7 years (standard deviation $(\mathrm{SD}), \pm 8.7$ years), compared to 62.6 years ( $\mathrm{SD} \pm 11.8$ years) and 63.2 years ( $\mathrm{SD} \pm 10.8$ years) for the training and validation cohorts, respectively. Notably, $66 \%$ of the Egyptian patients were 60 years or younger at the time of diagnosis. Among the Egyptian patients, $83 \%$ were male, with a higher male:female ratio (4.9:1) compared to the other cohorts. The Egyptian patients had higher $\alpha$-FP, ALT values, lower platelet and serum sodium ( $\mathrm{Na}$ ) level and more cirrhosis, vascular invasion, advanced CTP score, advanced BCLC stage, and systemic therapy usage compared with the other cohorts. Also, the mean coefficient for IGF-1 was 0.7 in the training cohort, 1.38 in MDACC validation cohort, and 0.42 in the Egyptian validation cohort

\section{Comparison of OS duration and prognostic accuracy by CTP score vs. IGF-CTP score}

The median OS duration in the Egyptian validation cohort was 8.05 months ( $95 \% \mathrm{CI}=6.9$ to 9.2 months), compared to 13.2 months ( $95 \% \mathrm{CI}=11.4$ to 16.6 months) in the training cohort and 15.7 months $(95 \% \mathrm{CI}=12.2$ to 19.9 months) in the MD Anderson validation cohort. Table 2 summarizes OS according to the plasma IGF-1 levels. Patients with a high IGF-1 level (>50 ng/ml) had significantly longer OS than those with intermediate and low IGF-1 levels, in the Egyptian validation cohort $(P<$ .0001); the same was true for both the training and MD Anderson validation cohorts $(P<.001)$.

Among all three cohorts, patients with low IGF-1 levels had statistically significantly shorter OS compared to patients with high IGF-1 levels. Patients with an intermediate IGF-1 level had shorter OS compared to patients with a high IGF-1 level, but this difference was not statistically significant in either validation cohort. Furthermore, patients with a low IGF-1 level had shorter OS compared to patients with an intermediate IGF-1 level 
Table 1: Baseline characteristics of patients in the training and validation cohorts.

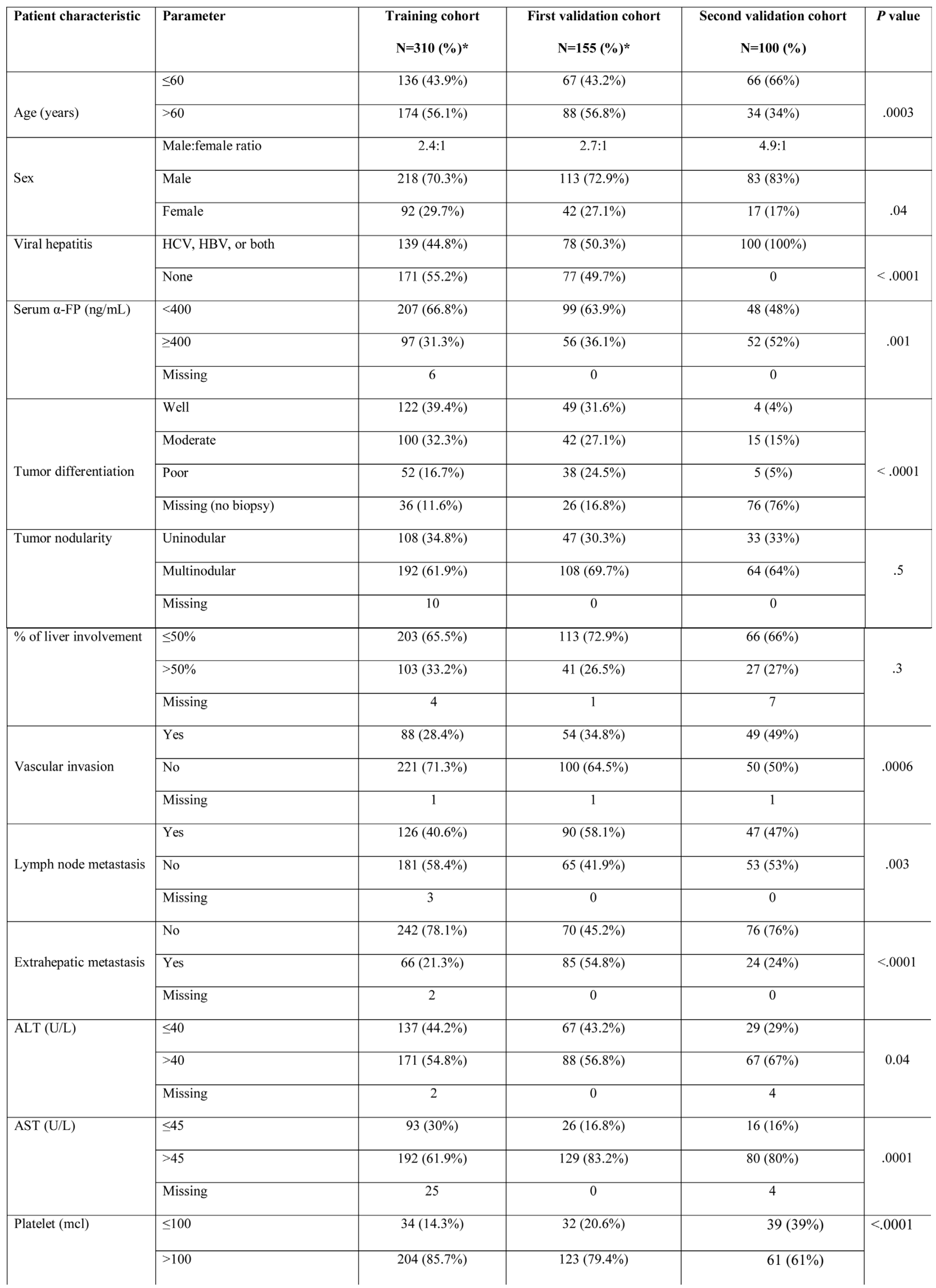




\begin{tabular}{|c|c|c|c|c|c|}
\hline & Missing & 72 & 0 & 0 & \\
\hline \multirow[t]{3}{*}{$\mathrm{Na}(\mathrm{mEq} / \mathrm{L})$} & $\leq 130$ & $10(3.3 \%)$ & $5(3.2 \%)$ & $25(29.4 \%)$ & \multirow[t]{3}{*}{$<.0001$} \\
\hline & $>130$ & $295(96.7 \%)$ & $149(96.8 \%)$ & $60(70.6 \%)$ & \\
\hline & Missing & 5 & 1 & 15 & \\
\hline \multirow[b]{2}{*}{ Cirrhosis } & No & $116(37.4 \%)$ & $52(36.4 \%)$ & $13(13 \%)$ & \multirow[b]{2}{*}{$<.0001$} \\
\hline & Yes & $194(62.6 \%)$ & $93(63.6 \%)$ & $87(87 \%)$ & \\
\hline \multirow{4}{*}{ CTP score } & A & $221(71.2 \%)$ & $126(81.3 \%)$ & $40(40 \%)$ & \multirow{4}{*}{$<.0001$} \\
\hline & B & $79(25.5 \%)$ & $25(16.1 \%)$ & $32(32 \%)$ & \\
\hline & $\mathrm{C}$ & $8(2.6 \%)$ & $4(2.6 \%)$ & $28(28 \%)$ & \\
\hline & Missing & 2 & 0 & 0 & \\
\hline \multirow{6}{*}{ BCLC stage } & 0 & $20(6.5 \%)$ & $2(1.3 \%)$ & 0 & \multirow{6}{*}{$<.0001$} \\
\hline & A & $27(8.7 \%)$ & $13(8.4 \%)$ & $1(1 \%)$ & \\
\hline & B & $30(9.7 \%)$ & $17(11 \%)$ & $8(8 \%)$ & \\
\hline & $\mathrm{C}$ & $196(63.2 \%)$ & $119(76.8 \%)$ & $60(60 \%)$ & \\
\hline & $\mathrm{D}$ & $23(7.4 \%)$ & $4(2.5 \%)$ & $31(31 \%)$ & \\
\hline & Missing & 14 & 0 & 0 & \\
\hline \multirow{4}{*}{ Treatment history } & Systemic \pm Local & $143(46.1 \%)$ & $89(57.4 \%)$ & $64(64 \%)$ & \multirow{4}{*}{$<.0001$} \\
\hline & Local therapy only (TACE/RFA) & $29(9.4 \%)$ & $40(25.8 \%)$ & $12(12 \%)$ & \\
\hline & Surgery \pm Local & $94(30.3 \%)$ & $15(9.7 \%)$ & $1(1 \%)$ & \\
\hline & Best supportive care & $44(14.2 \%)$ & $11(7.1 \%)$ & $23(23 \%)$ & \\
\hline
\end{tabular}

Abbreviations: $\mathrm{HCV}$, hepatitis C virus; HBV, hepatitis B virus; $\alpha$-FP, $\alpha$-fetoprotein; ALT, alanine transaminase; AST, aspartate transaminase; CTP, ChildTurcotte-Pugh; BCLC, Barcelona Clinic Liver Cancer; TACE, trans-arterial chemoembolization; RFA, radiofrequency ablation.

*Data reprinted from reference 15 with permission.

\section{MDACC Training Cohort}

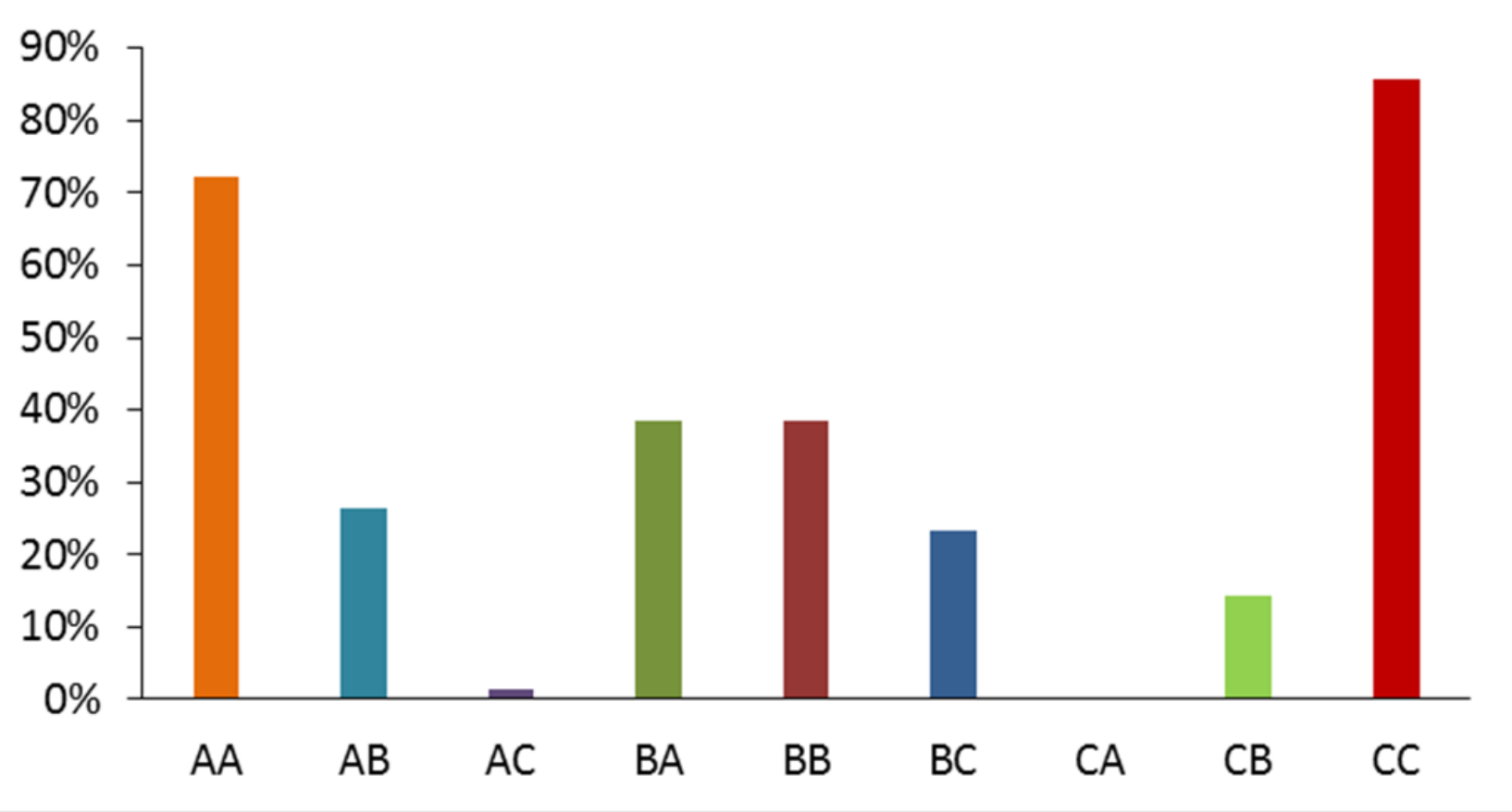


MDACC Validation Cohort
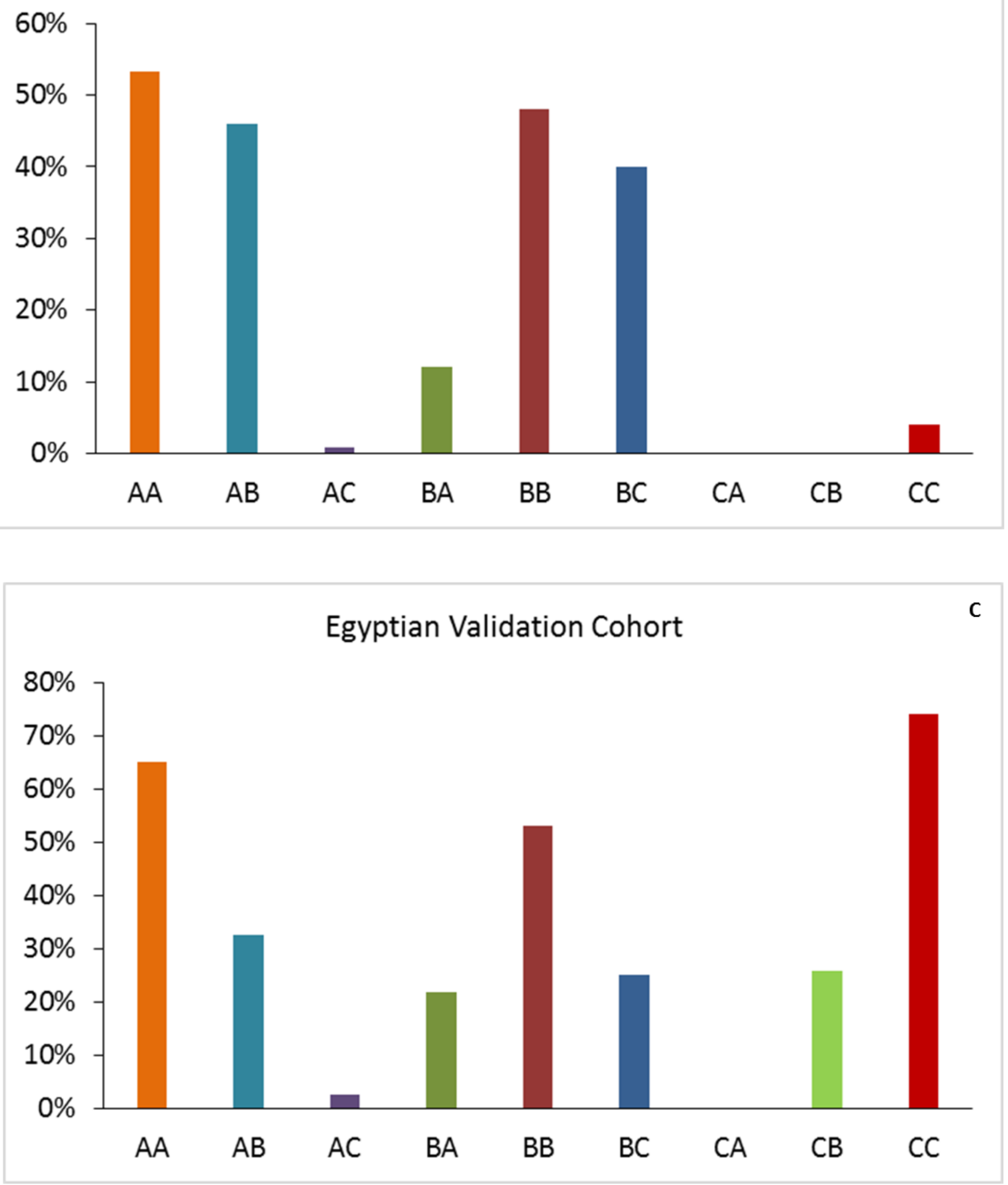

Figure 1: Patient distribution in the training and validation cohorts for IGF-CTP score class by CTP score class. The first letter for each group represents the CTP class; the second letter, the IGF-CTP class (e.g., group AB represents patients classified as CTP class A and IGF-CTP class B). 
Table 2: Log-rank and Cox model results for overall survival of the training and validation cohorts based on IGF-1 level.

\begin{tabular}{|c|c|c|c|c|c|c|c|c|c|c|c|c|c|}
\hline \multirow[b]{2}{*}{$\begin{array}{c}\text { Overall } \\
\text { survival by } \\
\text { IGF-1 level }\end{array}$} & \multirow[b]{2}{*}{$\begin{array}{c}\text { IGF-1 } \\
\text { level } \\
\text { (ng/mL) }\end{array}$} & \multicolumn{4}{|c|}{ Training cohort $(\mathrm{N}=310)$ * } & \multicolumn{4}{|c|}{ First validation cohort $(\mathrm{N}=155)$ * } & \multicolumn{4}{|c|}{ Second validation cohort $(\mathrm{N}=100)$} \\
\hline & & $\begin{array}{l}\text { No. } \\
(\%)\end{array}$ & $\mathbf{E}$ & $\begin{array}{l}\text { Median OS, } \\
\text { months } \\
(95 \% \mathrm{CI})\end{array}$ & $\begin{array}{c}P \\
\text { value }\end{array}$ & $\begin{array}{l}\text { No. } \\
(\%)\end{array}$ & $\mathbf{E}$ & $\begin{array}{l}\text { Median OS, } \\
\text { months } \\
(95 \% \text { CI })\end{array}$ & $\begin{array}{c}P \\
\text { value }\end{array}$ & $\begin{array}{l}\text { No. } \\
(\%)\end{array}$ & $\mathbf{E}$ & $\begin{array}{l}\text { Median OS, } \\
\text { months } \\
(95 \% \mathrm{CI})\end{array}$ & $P$ value \\
\hline All patients & & 310 & 238 & $\begin{array}{c}13.22 \\
(11.4 \text { to } 16.6)\end{array}$ & & 155 & 71 & $\begin{array}{c}15.7 \\
\text { (12.2 to } 19.9)\end{array}$ & & 100 & 100 & $\begin{array}{c}8.05 \\
\text { (6.9 to } 9.2)\end{array}$ & \\
\hline & $>50$ & $\begin{array}{c}133 \\
(42.9 \%)\end{array}$ & 92 & $\begin{array}{c}22.6 \\
\text { (15.1 to } 28.8)\end{array}$ & $<.001$ & $\begin{array}{c}61 \\
(39.4 \%)\end{array}$ & 24 & $\begin{array}{c}23.7 \\
(18.4 \text { to NA) }\end{array}$ & $<.001$ & $\begin{array}{c}44 \\
(44 \%)\end{array}$ & 33 & $\begin{array}{c}10.05 \\
(9.9 \text { to } 10.2)\end{array}$ & $<.0001$ \\
\hline & $26-50$ & $\begin{array}{c}109 \\
(35.2 \%)\end{array}$ & 85 & $\begin{array}{c}13.6 \\
(8.5 \text { to } 19.3)\end{array}$ & & $\begin{array}{c}17 \\
(10.9 \%)\end{array}$ & 5 & $\begin{array}{c}9.5 \\
(7.6 \text { to } \mathrm{NA})\end{array}$ & & $\begin{array}{c}20 \\
(20 \%)\end{array}$ & 18 & $\begin{array}{c}9.04 \\
(5.9 \text { to } 12.2)\end{array}$ & \\
\hline & $<26$ & $\begin{array}{c}68 \\
(21.9 \%)\end{array}$ & 61 & $\begin{array}{c}5.0 \\
(4.01 \text { to } 11.9)\end{array}$ & & $\begin{array}{c}77 \\
(49.8 \%)\end{array}$ & 42 & $\begin{array}{c}9.4 \\
(6.4 \text { to } 14.74)\end{array}$ & & $\begin{array}{c}36 \\
(36 \%)\end{array}$ & 33 & $\begin{array}{c}8.05 \\
(6.9 \text { to } 9.2)\end{array}$ & \\
\hline $\begin{array}{l}\text { Hazard } \\
\text { ratios by }\end{array}$ & & & & $\begin{array}{c}\text { HR } \\
(95 \% \mathrm{CI})\end{array}$ & $\begin{array}{c}P \\
\text { value }\end{array}$ & & & $\begin{array}{c}\text { HR } \\
(95 \% \mathrm{CI})\end{array}$ & $\begin{array}{c}P \\
\text { value }\end{array}$ & & & $\begin{array}{c}\text { HR } \\
(95 \% \mathrm{CI})\end{array}$ & $P$ value \\
\hline & $>50$ & - & 一 & 1.00 (reference) & & & & 1.00 (reference) & & 一 & - & 1.00 (reference) & \\
\hline & $26-50$ & - & - & $\begin{array}{c}1.45 \\
(1.08 \text { to } 1.95)\end{array}$ & .01 & & & $\begin{array}{c}1.26 \\
(0.48 \text { to } 3.33)\end{array}$ & .64 & - & - & $\begin{array}{c}1.4 \\
(0.81 \text { to } 2.58)\end{array}$ & .22 \\
\hline & $<26$ & - & - & 2.5 & $<.001$ & & & 2.81 & $<.001$ & - & - & 5.16 & $<.0001$ \\
\hline & & & & (1.8 to 3.47$)$ & & & & $(1.68$ to 4.68$)$ & & & & (2.99 to 8.9$)$ & \\
\hline & & 一 & - & & & & & & & - & - & & \\
\hline & $26-50$ & 一 & - & 1.00 (reference) & - & & & 1.00 (reference) & & 一 & 一 & 1.00 (reference) & \\
\hline & $<26$ & 一 & - & $\begin{array}{c}1.72 \\
(1.24 \text { to } 2.4)\end{array}$ & .001 & & & $\begin{array}{c}2.28 \\
(0.9 \text { to } 5.76)\end{array}$ & .08 & - & - & $\begin{array}{c}3 . \\
(1.76 \text { to } 6.6)\end{array}$ & $<.0001$ \\
\hline
\end{tabular}

Abbreviations: N, number; E, event (death); OS, overall survival; CI, confidence interval; IGF-1, insulin-like growth factor-1; NA, not available

*Data reprinted from reference 15 with permission.

in the Egyptian validation cohort $(P<0.0001)$, as well as in the training cohort $(P=0.001)$. In the MD Anderson validation cohort, patients with a low IGF-1 level had a worse prognosis than that of patients with an intermediate IGF-1 level, but this difference was not statistically significant $(\mathrm{HR}=2.28, P=0.082)$.

Table 3 shows that median OS was statistically significantly correlated with different risk groups in both scoring systems. Concordance index (C-index) yields values ranging from 0 (no discrimination) to 1 (perfect separation) to compare different prognostic systems. It has been previously used in the landmark paper that reported MELD score to determine organ allocation priorities.[16] C-index analysis (Table 4) demonstrated that the differences between $\mathrm{C}$-indices were not large, but the prognostic stratification provided by IGF-CTP score was statistically significant compared to CTP score in the
Egyptian validation cohort $(P=0.003)$ as well as in the training cohort $(P=0.003)$ and MD Anderson validation cohort $(P=0.005)$. Similarly, MELD score study reported a C-index of 0.83 for MELD score as compared to 0.76 for the CTP. Notably, the difference between C-indices was not large $(=0.07)$, however, it was statistically significant, $P<0.001$. This is because the $\mathrm{C}$-index computes the prognostic score ability to predict $\mathrm{OS}$ for all patients in the cohort, including those whose CTP and IGF-CTP scores were different and those whose scores were the same. To better understand this improvement, we focused on the patients who were classified into different risk groups by the two scoring systems. 
Table 3: Log-rank and Cox model results for overall survival of the training and validation cohorts by Child-Turcotte-Pugh (CTP) and IGF-CTP class.

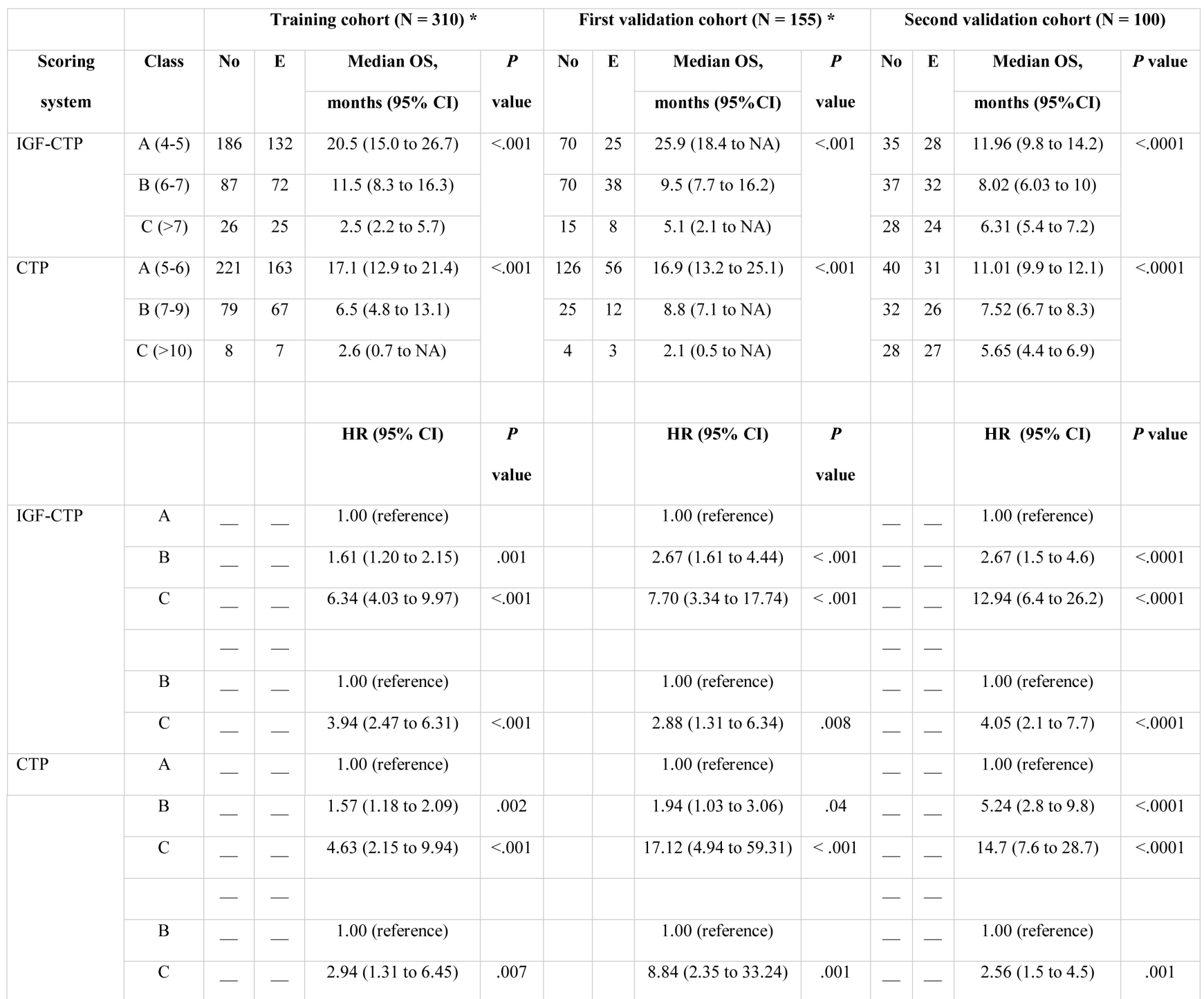

Abbreviations: N, number; E, event (death); OS, overall survival; CI, confidence interval; NA, not applicable; CTP, Child-Turcotte-Pugh; IGF, insulin-like growth factor-1.

*Parameters from 11 and two patients were not available for calculation of their IGF-CTP and CTP scores, respectively.

*Data reprinted from reference 15 with permission.

Table 4: Ranking of scoring systems by $\mathrm{C}$-index.

\begin{tabular}{|c|c|c|c|}
\hline Patient cohort & Scoring system & C-index (95\% CI) & $P$ value \\
\hline Training cohort & IGF-CTP & $0.608(0.606$ to 0.610$)$ & .003 \\
\hline $\mathrm{N}=310^{*}$ & CTP & $0.573(0.571$ to 0.575$)$ & \\
\hline First validation cohort & IGF-CTP & $0.672(0.666$ to 0.677$)$ & .005 \\
\hline $\mathrm{N}=155^{*}$ & CTP & $0.579(0.576$ to 0.583$)$ & \\
\hline Second validation cohort & IGF-CTP & $0.641(0.637$ to 0.645$)$ & \\
\hline $\mathrm{N}=\mathbf{1 0 0}$ & CTP & $0.597(0.596$ to 0.601$)$ & .003 \\
\hline
\end{tabular}

Abbreviations: IGF, insulin-like growth factor-1; CTP, Child-Turcotte-Pugh; N, number; CI, confidence interval.

*Data reprinted from reference 15 with permission. 


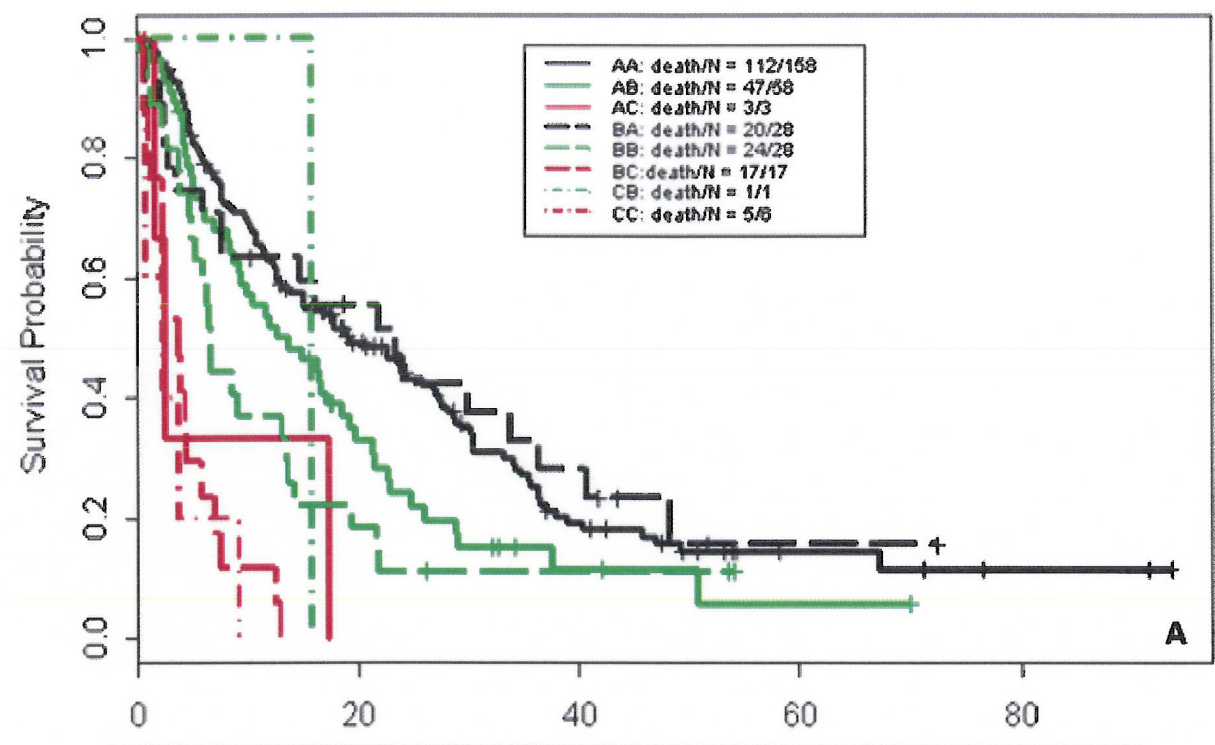

\begin{tabular}{lllll}
\hline Group & \multicolumn{3}{c}{ Survival time (months) } \\
\hline AA158 & 60 & 19 & 5 & 2 \\
\hline AB58 & 15 & 3 & 1 & 0 \\
\hline AC3 & 0 & 0 & 0 & 0 \\
\hline BA28 & 13 & 6 & 1 & 0 \\
\hline BB28 & 5 & 2 & 0 & 0 \\
\hline BC17 & 0 & 0 & 0 & 0 \\
\hline CB1 & 0 & 0 & 0 & 0 \\
\hline CC6 & 0 & 0 & 0 & 0
\end{tabular}

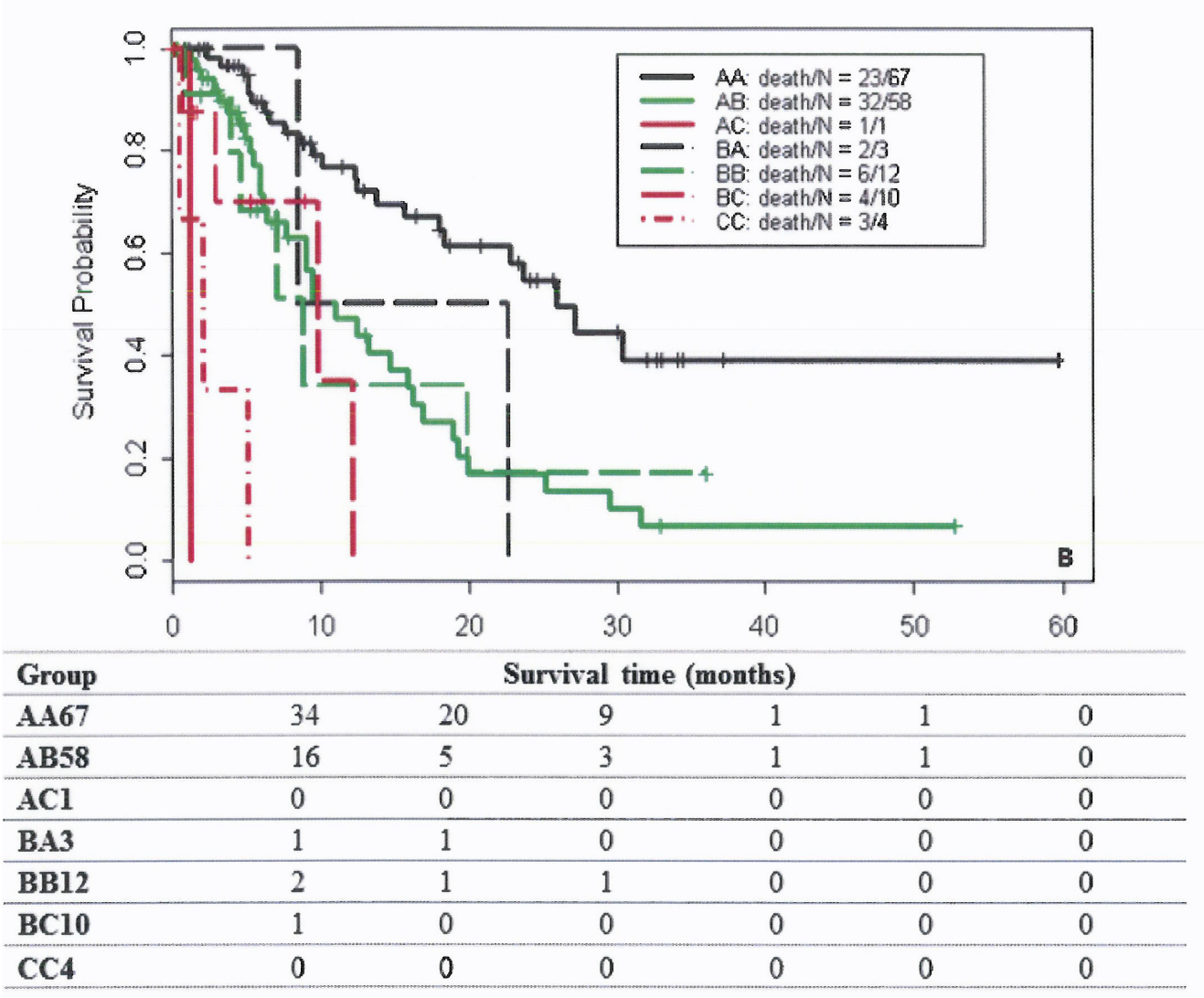




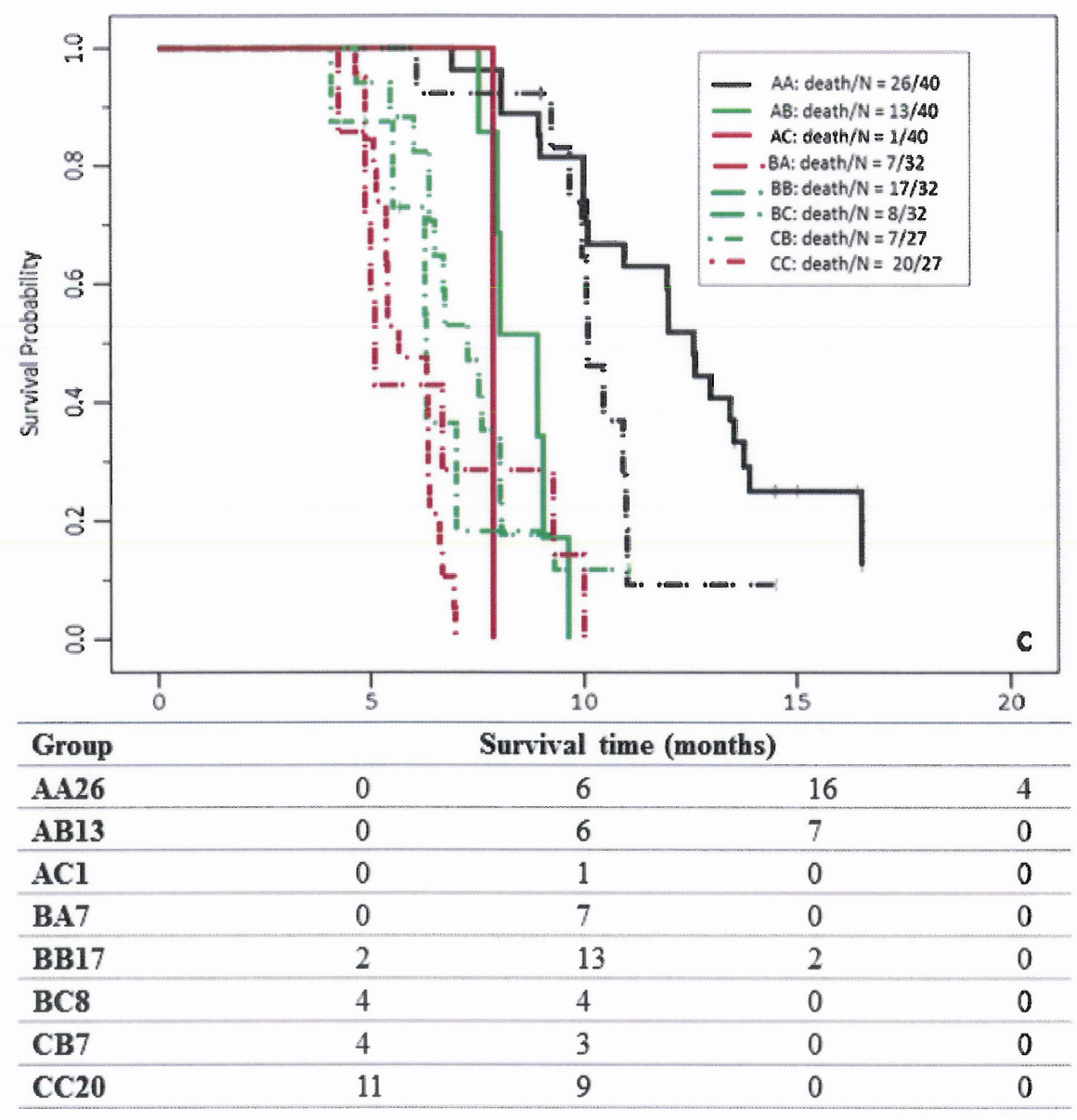

Figure 2: Survival curves of patients classified by group in the training cohort (A), MDACC validation cohort (B), and Egyptian validation cohort $(\mathbf{C})$. The first letter for each group represents the CTP class; the second letter, the IGF-CTP class (e.g., group $\mathrm{AB}$ represents patients classified as CTP class A and IGF-CTP class B).

\section{Reassignment of patients from CTP classes to different IGF-CTP classes}

We found that $63 \%$ of patients in the Egyptian cohort were classified in the same risk groups by both scoring systems, compared to $61.9 \%$ in the training cohort and $53.5 \%$ in the MD Anderson validation cohort (Figure 1). Comparison of OS durations (Table 5) and KaplanMeier survival curves (Figure 2) showed a significant difference when patients were stratified with the IGF-CTP score compared to the original CTP score.

In the Egyptian validation cohort, 26/40 (65\%) of the patients with CTP class A were classified as IGFCTP-A (AA), and they had an OS duration of 12.58 months (95\% CI=11.7 to 13.4 months). While, $13 / 40$ $(32.5 \%)$ were reclassified as IGF-CTP-B (AB), and they had significantly worse OS of 8.9 months $(95 \% \mathrm{CI}=7.8$ to 10 months) compared to group AA. Only one patient was reclassified as IGF-CTP-C (AC). Patients reclassified from CTP-A to IGF-CTP-B (AB) or IGF-CTP-C (AC) had worse prognosis compared to patients who were classified as $\mathrm{AA}(\mathrm{HR}=6.15 ; P=0.001$ and $\mathrm{HR}=10.11 ; P=.03$, respectively).

Moreover, patients who were reclassified from CTP-B to IGF-CTP-A (BA) had better prognosis compared to patients who were classified as $\mathrm{BB}(\mathrm{HR}=0.37 ; P=$ $0.02)$. Finally, the majority of CTP-C patients remained in class $\mathrm{C}$ according to the IGF-CTP scoring system. Only $7 / 27(25.9 \%)$ were reclassified as IGF-CTP-B, and their OS duration was 8.05 months $(95 \% \mathrm{CI}=6.9$ to 9.2 months); this duration did not differ significantly when compared to patients who were classified as $\mathrm{CC}(\mathrm{OS}=5.65$ months; $\mathrm{HR}=0.42 ; 95 \% \mathrm{CI}=0.15$ to $1.19 ; P=0.103$ ).

\section{DISCUSSION}

In this study in an Egyptian population, we have validated the plasma level of IGF-1 as a surrogate marker for functional liver reserve and the value of its integration into the CTP scoring system in place of encephalopathy and ascites. We conclude that the IGF-CTP scoring system is associated with significantly better HCC patient stratification and survival prediction not only in the U.S. 
Table 5: Overall survival of the training and validation cohorts by whether CTP class was reclassified in the IGF-CTP scoring system.

\begin{tabular}{|c|c|c|c|c|c|c|c|c|c|c|c|c|}
\hline & \multicolumn{4}{|c|}{ Training cohort $(\mathrm{N}=310)$ * } & \multicolumn{4}{|c|}{ First validation cohort $(\mathrm{N}=155)$ * } & \multicolumn{4}{|c|}{ Second validation cohort $(\mathrm{N}=100)$} \\
\hline & $\mathbf{N}$ & $\mathbf{E}$ & $\begin{array}{l}\text { Median OS, months } \\
(95 \% \mathrm{CI})\end{array}$ & $P$ value & $\mathbf{N}$ & $\mathbf{E}$ & $\begin{array}{l}\text { Median OS, months } \\
(95 \% \mathrm{CI})\end{array}$ & $P$ value & $\mathbf{N}$ & $\mathbf{E}$ & $\begin{array}{l}\text { Median OS, months } \\
(95 \% \mathrm{CI})\end{array}$ & $P$ value \\
\hline $\begin{array}{l}\text { Original A to } \\
\text { new A (AA) }\end{array}$ & 158 & 112 & $19.3(14.9$ to 27.0$)$ & $<0.001^{\natural}$ & 67 & 23 & $25.9(18.4$ to NA) & $<0.001^{\prime \prime}$ & 26 & 20 & $12.58(11.7$ to 13.4$)$ & $<0.0001^{4}$ \\
\hline $\begin{array}{l}\text { Original A to } \\
\text { new } B(A B)\end{array}$ & 58 & 47 & $13.6(9.1$ to 19.7$)$ & & 58 & 32 & $11.0(7.7$ to 16.9$)$ & & 13 & 10 & $8.9(7.8$ to 10$)$ & \\
\hline $\begin{array}{l}\text { Original A to } \\
\text { new C (AC) }\end{array}$ & 3 & 3 & $2.3(1.5$ to $\mathrm{NA})$ & & 1 & 1 & 1.2 (NA to NA) & & 1 & 1 & 7.85 (NA to NA) & \\
\hline $\begin{array}{l}\text { Original B to } \\
\text { new A (BA) }\end{array}$ & 28 & 20 & $23.5(7.6$ to 40.6$)$ & & 3 & 2 & $15.6(8.5$ to $\mathrm{NA})$ & & 7 & 7 & $10.09(9.5$ to 10.7$)$ & \\
\hline $\begin{array}{l}\text { Original B to } \\
\text { new B (BB) }\end{array}$ & 28 & 24 & $6.5(5.1$ to 13.6$)$ & & 12 & 6 & 8.8 (4.6 to NA ) & & 17 & 15 & $7.26(6.2$ to 8.4$)$ & \\
\hline $\begin{array}{l}\text { Original } B \text { to } \\
\text { new } C(B C)\end{array}$ & 17 & 17 & $3.7(2.2$ to 6.9$)$ & & 10 & 4 & 9.8 (2.9 to NA) & & 8 & 5 & $5.09(4.8$ to 5.3$)$ & \\
\hline $\begin{array}{l}\text { Original } \mathrm{C} \text { to } \\
\text { new } \mathrm{A}(\mathrm{CA})\end{array}$ & 0 & - & - & & 0 & - & - & & 0 & - & - & \\
\hline $\begin{array}{l}\text { Original } \mathrm{C} \text { to } \\
\text { new } \mathrm{B}(\mathrm{CB})\end{array}$ & 1 & 1 & 15.9 (NA to NA) & & 0 & - & - & & 7 & 7 & $8.05(6.9$ to 9.2$)$ & \\
\hline $\begin{array}{l}\text { Original } \mathrm{C} \text { to } \\
\text { new } \mathrm{C}(\mathrm{CC})\end{array}$ & 6 & 5 & $2.3(0.7$ to NA $)$ & & 4 & 3 & $2.1(0.5$ to $\mathrm{NA})$ & & 20 & 19 & 5.65 (4.6 to 6.7$)$ & \\
\hline & & & HR $(95 \%$ CI) & $P$ value & & & HR (95\% CI) & $P$ value & & & HR $(95 \%$ CI) & $P$ value \\
\hline AA & & & 1.00 (reference) & & & & 1.00 (reference) & & & & 1.00 (reference) & \\
\hline $\mathrm{AB}$ & & & $1.45(1.03$ to 2.04$)$ & .03 & & & $2.83(1.65$ to 4.85$)$ & $<.001$ & & & $6.15(2.18$ to 17.37$)$ & .001 \\
\hline $\mathrm{AC}$ & & & 4.05 (1.28 to 12.83$)$ & .02 & & & NA & NA & & & $10.11(1.25$ to 81.75$)$ & .03 \\
\hline $\mathrm{BA}$ & & & $0.95(0.59$ to 1.53$)$ & .84 & & & $2.63(0.62$ to 11.23$)$ & .19 & & & $2.02(0.91$ to 4.46$)$ & .08 \\
\hline BB & & & $2.0(1.28$ to 3.11$)$ & .002 & & & $2.87(1.17$ to 7.08$)$ & .02 & & & $6.83(3.15$ to 14.78$)$ & $<.0001$ \\
\hline $\mathrm{BC}$ & & & $6.45(3.78$ to 11.01$)$ & $<.001$ & & & 4.66 (1.57 to 13.86$)$ & .006 & & & 11.93 (4.55 to 31.3$)$ & $<.0001$ \\
\hline $\mathrm{CB}$ & & & $1.69(0.24$ to 112.16$)$ & .60 & & & NA & NA & & & 14.25 (4.67 to 43.48$)$ & $<.0001$ \\
\hline $\mathrm{CC}$ & & & 8.94 (3.59 to 22.23$)$ & $<.001$ & & & $32.39(8.86$ to 118.49$)$ & $<.001$ & & & $37.36(15.05$ to 92.74$)$ & $<.0001$ \\
\hline BB & & & 1.00 (reference) & & & & 1.00 (reference) & & & & 1.00 (reference) & \\
\hline $\mathrm{AB}$ & & & $0.73(0.44$ to 1.19$)$ & .20 & & & $0.98(0.41$ to 2.36$)$ & .97 & & & $0.94(0.35$ to 2.49$)$ & .89 \\
\hline $\mathrm{AC}$ & & & $2.03(0.61$ to 6.77$)$ & .25 & & & NA & NA & & & $1.46(0.19$ to 11.34$)$ & .72 \\
\hline $\mathrm{BA}$ & & & $0.48(0.26$ to 0.87$)$ & .03 & & & $0.92(0.18$ to 4.57$)$ & .91 & & & $0.37(0.16$ to 0.83$)$ & .02 \\
\hline $\mathrm{BC}$ & & & $3.23(1.72$ to 6.09$)$ & $<.001$ & & & $1.62(0.45$ to 5.86$)$ & .46 & & & $1.891(0.75$ to 4.79$)$ & .18 \\
\hline $\mathrm{CB}$ & & & $0.85(0.11$ to 6.28$)$ & .87 & & & NA & NA & & & $2.23(0.78$ to 6.41$)$ & .14 \\
\hline $\mathrm{CC}$ & & & $4.48(1.69$ to 11.8$)$ & .003 & & & 11.27 (2.64 to 48.14$)$ & .001 & & & $5.41(2.42$ to 12.1$)$ & $<.0001$ \\
\hline
\end{tabular}




\begin{tabular}{|c|c|c|c|c|c|c|}
\hline $\mathrm{CC}$ & 1.00 (reference) & & 1.00 (reference) & & 1.00 (reference) & \\
\hline $\mathrm{AB}$ & $0.11(0.05$ to 0.28$)$ & $<.001$ & $0.09(0.02$ to 0.31$)$ & $<.001$ & $0.18(0.06$ to 0.52$)$ & .002 \\
\hline $\mathrm{AC}$ & $0.45(0.11$ to 1.91$)$ & .28 & NA & NA & 0.3 (0.04 to 2.35$)$ & .25 \\
\hline BA & $0.11(0.04$ to 0.29$)$ & $<.001$ & $0.08(0.01$ to 0.52$)$ & .008 & $0.03(0.007$ to 0.11$)$ & $<.0001$ \\
\hline $\mathrm{BC}$ & $0.72(0.27$ to 1.96$)$ & .52 & $0.14(0.03$ to 0.68$)$ & .01 & $0.27(0.09$ to 0.85$)$ & .03 \\
\hline $\mathrm{CB}$ & $0.19(0.02$ to 1.63$)$ & .13 & NA & NA & $0.42(0.15$ to 1.19$)$ & .103 \\
\hline
\end{tabular}

Abbreviations: IGF, insulin-like growth factor-1; CTP, Child-Turcotte-Pugh; N, number; E, event(death); NA, not applicable; OS, overall survival.

${ }^{\uparrow} P$ value compares across all groups.

*Data reprinted from reference 15 with permission

populations originally tested but also in our validation population, who had different demographics, geographical location, and HCC risk factors than those previously reported.

Notably, HCC is a heterogeneous disease because of variation in the underlying cause, with subsequent variation in the mechanism of development. In the USA, $40 \%$ of $\mathrm{HCC}$ cases are attributed to chronic HCV infection alone. In Egypt, the incidence of HCC has been soaring over the past two decades, and it is now the most common cancer in Egyptian men, related to HCV in up to $94 \%$ of cases.[17-19]

Furthermore, there is variation in HCV genotypes: up to six types and more than 80 subtypes exist.[20] In the United States, $70 \%$ of cases have HCV genotype $1 \mathrm{a} / 1 \mathrm{~b}$, $15-20 \%$ genotype 2 , about $10 \%$ genotype $3,1 \%$ genotype 4 and less than 1\% genotypes 5 and 6.[21] In contrast, in Egypt, the prevalence of genotype $4 \mathrm{a} / 4 \mathrm{~b}$ is $91 \%$; among those, $63 \%$ are genotype 4a.[22-24] Previous studies[25, 26] showed a higher rate of recurrent advanced fibrosis following liver transplantation among patients with recurrent $\mathrm{HCV}$ genotype 4 infection compared to other genotypes. This association of liver fibrosis and $\mathrm{HCV}$ genotype 4 infection could explain the higher rate of advanced cirrhosis in Egyptian HCC patients.

In our study, $66 \%$ of the Egyptian patients were diagnosed at a younger age, a higher percentage compared to U.S. patients. The Egyptian patients had a statistically significant higher $\alpha$-FP and ALT level with more incidence of cirrhosis, vascular invasion, advanced CTP score, advanced BCLC stage, and systemic therapy usage. These findings suggest a more aggressive nature of the disease among Egyptian patients and subsequently their lower hepatic reserve capacity. Therefore, developing a more sensitive tool to assess hepatic reserve is critical to this patient population management.

Furthermore, while surgical resection and liver transplantation are the only curative treatment for HCC, unfortunately, most patients are not surgical candidates due to either advanced disease at the time of presentation and/or advanced underlying CLD. Therefore, assessing hepatic reserve in $\mathrm{HCC}$ is expected to have a great impact on treatment decision and predicted patients' overall survival in addition to stratification and recruitment of patients for clinical trials and estimation of patients' OS.[27].

Notably, sorafenib is the only systemic treatment approved for treatment of CTP-A HCC patients. [28, 29] However, its high cost adds a significant burden to health care system budgets. Since Egypt, which is considered a lower-middle-income country by the World Bank[30] and the International Monetary Fund,[31] has limited resources, it is thus particularly important to identify which HCC patients will benefit from sorafenib as distinct from those in whom sorafenib will pose higher rate of adverse events and lower survival benefit. In this context, applying a simple, noninvasive, low cost marker for liver reserve assessment will be helpful.[32].

CTP is the standard tool used to assess underlying liver reserve within major HCC staging systems such as Cancer of the Liver Italian Program (CLIP), and BCLC. Several studies have concluded that only patients with CTP class A are likely to benefit from active treatment and enrollment into clinical trials, while patients with CTP class $\mathrm{B}$ or $\mathrm{C}$ disease have significantly decreased survival expectancy due to the deterioration in hepatic function compared to class A. $[3,4]$ When comparing the results of the new IGF-CTP score in this international validation cohort with those of our previous training and validation cohorts at MD Anderson, we found that in all three groups, some patients with CTP-A were reclassified into by IGF-CTP scoring system into classes B and C; these patients had poorer hepatic reserve and therefore shorter OS. Accurate selection of patients with CTP class A is extremely important in the clinical practice because these group of patients who are illegible for active treatment. On the contrary, some patients with CTP-B were reclassified as class A based on the new scoring system and had a longer OS but they prohibited from receiving active treatment based on the original CTP score that classify them as class B. Therefore, the new IGF-CTP score could led to more precise ability to select patients who will benefit from treatment (class A).

The major strength of our study is that this is the first international validation of the IGF-CTP score, and it is tested through an independent prospective 
validation cohort in patients with different demographics, geographical location, hepatitis status and other HCC risk factors from those of the original cohorts. In the Egyptian cohort, all patients had viral-induced HCC, compared with only $44.8 \%$ in the training cohort and $50.3 \%$ in the first validation cohort. Our findings help to identify the prognostic significance of this score in patients who have more advanced disease and marked impairment of the liver capacity both by HCC as a space-occupying lesion and by the underlying viral hepatitis, which is mainly induced by HCV genotype 4, with a higher degree of liver fibrosis. Another strength of this study is that since the majority of patient's had unresectable disease; the main pool of patients undergoing systemic and local therapies in routine practice and clinical trials; accurate assessment of hepatic reserve and subsequent prediction of patient's prognosis and survival in this group of patients is very important to identify who will get benefit from active therapy and potential enrollment in clinical trials.

"Our study has some limitations. First, the majority of patients had unresectable disease. However, predicting patient's prognosis and survival in this group of patients is very important to identify who will benefit from systemic therapy and potential enrollment in clinical trials. Second, we don't have complete data regarding alcohol intake. However, all cases were viral related and therefore cirrhosis in the Egyptian population was mainly related to hepatitis virus. Finally, A limitation of our study was that it didn't allow us to test the predictive value of the IGF-CTP score for the outcome of different treatment modalities. Therefore, future studies to evaluate the predictive ability of IGF score in systemic and local therapies are warranted".

Despite the CTP score's limitations, it is still the only standard tool parameter for assessing underlying liver reserve capacity within the most clinically used staging systems as CLIP, CUPI, and BCLC. So, this will affect patient staging and subsequantly selecting the suitable treatment, predicting treatment outcome, and identifing patients who are eligible to be enrolled in clinical trials. In the current study, we validate the value of incorporating plasma IGF-1 level instead of encephalopathy and ascites as parameters of the CTP score to create a new scoring system, Kaseb-Morris IGF-CTP system.

The new IGF-CTP score significantly improved selection of patients who were candidates for treatment and prediction of survival outcome. Since the majority of HCC staging systems include CTP score in their parameters, 1 future studies to assess the value of integrating IGF-CTP score instead of CTP score in these staging systems may lead to more accurate patient stratification and treatment selection." After further validation in HCC patients with different demographics and risk factors, the new IGFCTP score may help to improve prediction of survival outcomes and rate of therapy adverse events which may subsequently aid in better selection of patients who are candidates for active HCC treatment and in prediction of survival outcome. Finally, since the majority of HCC staging systems include CTP score in their parameters as a liver assessment tool, 1 future studies to assess the value of integrating IGF-CTP score instead of CTP score in these staging systems may lead to more accurate patient stratification and treatment selection.

\section{PATIENTS AND METHODS}

\section{Study design and study population}

We recruited $100 \mathrm{HCC}$ patients from Assiut University Hospital, Egypt, from April 2012 to September 2013. We compared our cohort with two previous cohorts: i) prospectively recruited $\mathrm{HCC}$ patients who presented at MD Anderson Cancer Center from January 2000 to May 2008 and were used as a training cohort, and ii) prospectively recruited HCC patients who presented at MD Anderson between June 2008 and September 2011 and were used as a validation cohort. This study was approved by the institutional review boards of MD Anderson and Assiut University Hospital. Written informed consent for study participation was obtained from each patient. For all three HCC cohorts, the study involved pathologically confirmed HCC or radiologically confirmed HCC based on American Association for the Study of Liver Diseases guidelines[33] for patients enrolled after 2005 who did not have available biopsy samples.

Detailed data on patients' demographics, risk factors, and clinicopathological features were collected. The clinical data included information about Eastern Cooperative Oncology Group (ECOG) performance status; levels of alpha-fetoprotein ( $\alpha-\mathrm{FP})$, aspartate transaminase (AST), and alanine transaminase (ALT;presence of cirrhosis; tumor nodularity; volume of the liver occupied by the tumor; vascular invasion; lymph node metastasis; extrahepatic metastasis; CTP score; Barcelona Clinic Liver Cancer (BCLC) stage; and treatment history. We followed standard approach to calculate CTP score, by using clinical judgment and imaging studies to assess ascites and encephalopathy which is currently the standard approach in routine practice and clinical trials, therefore limited since it is subjective parameters and influenced by other factors

Blood samples for IGF-1 analysis were prospectively collected and analyzed for IGF-1 in our cohort. Our data were compared with the IGF-1 values in the training cohort, for which samples were prospectively collected and retrospectively analyzed, and in the validation cohort, for which samples were prospectively collected and analyzed. 


\section{Baseline plasma IGF-1 level}

Peripheral venous blood samples (3-5 mL) were collected, anticoagulated by ethylenediaminetetraacetic acid (EDTA), and centrifuged at $4{ }^{\circ} \mathrm{C}$ for 15 minutes at 3000 RPM. Then the plasma samples were removed, aliquoted, and snap-frozen at $-20^{\circ} \mathrm{C}$ until analyzed.

In both the training cohort and the Egyptian validation cohort, IGF-1 was tested by enzyme-linked immunosorbent assay (ELISA) according to the manufacturer's directions (Quantikine Human IGF-1 ELISA Kit; R\&D Systems, Minneapolis, MN). In the MD Anderson validation cohort, plasma IGF-1 was tested at a Clinical Laboratory Improvement Amendments (CLIA)-certified facility that uses Luminex microsphere technology by Myriad Laboratories (Austin, Texas).

\section{IGF-CTP score}

Patients' IGF-CTP scores were calculated and class $\mathrm{A}, \mathrm{B}$, or $\mathrm{C}$ assigned based on their serum bilirubin level, serum albumin level, prothrombin time, and plasma IGF-1 level as described previously.[15]

\section{Statistical analysis}

We used IBM SPSS Statistics for Windows, Version 21.0 (IBM Corp., Armonk, NY) for data management and statistical analysis. Univariate analysis was done using chi-square or Fisher's exact test for categorical variables and the Kruskal-Wallis test for continuous variables. The Kaplan-Meier method was used to estimate the median overall survival (OS), which was defined as the time interval between the date of the blood draw for IGF1 measurement and the date of death or last follow-up. Also, the log-rank test was used to detect the statistical significance between the CTP score and the new IGF-CTP score subgroups. Then, we used the Cox proportional hazard model to calculate hazard ratios (HRs) and 95\% confidence intervals $(95 \%$ CIs) to identify independent prognostic factors for OS. Finally, we calculated the Harrell's C-index to compare the prognostic performance of both scores among the three cohorts. For all statistical analyses, a two-sided $P$ value as a descriptive measure was considered statistically significant if less than 0.05 .

\section{ACKNOWLEDGMENTS}

Editorial assistance was provided by Sunita Patterson of MD Anderson's Department of Scientific Publications.

\section{CONFLICTS OF INTEREST}

All authors report no commercial associations (e.g., consultancies, stock ownership, equity interests, or patent-licensing arrangements) that might pose a conflict of interest in connection with the submitted article.

\section{FUNDING}

This work was supported by the National Institutes of Health through grants CA170035-01 (to A.O.K.), CA106458-01 (to M.M.H.), R01 CA151533 (to H.M.A.) and by the Egyptian Ministry of Higher Education (through a scholarship to R.A.). The contents of this paper are solely the responsibility of the authors and do not necessarily represent the official views of the National Cancer Institute or the National Institutes of Health.

\section{REFERENCES}

1. Vauthey JN, Dixon E, Abdalla EK, Helton WS, Pawlik TM, Taouli B, Brouquet A and Adams RB. Pretreatment assessment of hepatocellular carcinoma: expert consensus statement. HPB 2010; 12:289-299.

2. Pugh RN, Murray-Lyon IM, Dawson JL, Pietroni MC and Williams R. Transection of the oesophagus for bleeding oesophageal varices. The British journal of surgery. 1973; 60:646-649.

3. Llovet JM, Di Bisceglie AM, Bruix J, Kramer BS, Lencioni R, Zhu AX, Sherman M, Schwartz M, Lotze M, Talwalkar $\mathrm{J}$ and Gores GJ. Design and endpoints of clinical trials in hepatocellular carcinoma. Journal of the National Cancer Institute. 2008; 100:698-711.

4. Wilson SR, Greig P and Kaseb AO. Pretreatment assessment of hepatocellular cancer: expert consensus conference. HPB : the official journal of the International Hepato Pancreato Biliary Association. 2010; 12:300-301.

5. Kim HJ and Lee HW. Important predictor of mortality in patients with end-stage liver disease. Clinical and molecular hepatology. 2013; 19:105-115.

6. Durand F and Valla D. Assessment of the prognosis of cirrhosis: Child-Pugh versus MELD. Journal of hepatology. 2005; 42 Suppl:S100-107.

7. Oellerich M, Burdelski M, Lautz HU, Rodeck B, Duewel J, Schulz M, Schmidt FW, Brodehl J and Pichlmayr R. Assessment of pretransplant prognosis in patients with cirrhosis. Transplantation. 1991; 51:801-806.

8. Testa R, Valente U, Risso D, Caglieris S, Giannini E, Fasoli A, Botta F, Dardano G, Lantieri PB and Celle G. Can the MEGX test and serum bile acids improve the prognostic ability of Child-Pugh's score in liver cirrhosis? European journal of gastroenterology \& hepatology. 1999; 11:559563.

9. Said A, Williams J, Holden J, Remington P, Gangnon R, 
Musat A and Lucey MR. Model for end stage liver disease score predicts mortality across a broad spectrum of liver disease. Journal of hepatology. 2004; 40:897-903.

10. Pessione F, Ramond MJ, Peters L, Pham BN, Batel P, Rueff $\mathrm{B}$ and Valla DC. Five-year survival predictive factors in patients with excessive alcohol intake and cirrhosis. Effect of alcoholic hepatitis, smoking and abstinence. Liver Int. 2003; 23:45-53

11. Botta F, Giannini E, Romagnoli P, Fasoli A, Malfatti F, Chiarbonello B, Testa E, Risso D, Colla G and Testa R. MELD scoring system is useful for predicting prognosis in patients with liver cirrhosis and is correlated with residual liver function: a European study. Gut. 2003; 52:134-139.

12. Malinchoc M, Kamath PS, Gordon FD, Peine CJ, Rank $\mathrm{J}$ and ter Borg PC. A model to predict poor survival in patients undergoing transjugular intrahepatic portosystemic shunts. Hepatology. 2000; 31:864-871.

13. Kaseb AO, Abbruzzese JL, Vauthey JN, Aloia TA, Abdalla EK, Hassan MM, Lin E, Xiao L, El-Deeb AS, Rashid A and Morris JS. I-CLIP: improved stratification of advanced hepatocellular carcinoma patients by integrating plasma IGF-1 into CLIP score. Oncology. 2011; 80:373-381.

14. Kaseb AO, Morris JS, Hassan MM, Siddiqui AM, Lin E, Xiao L, Abdalla EK, Vauthey JN, Aloia TA, Krishnan S and Abbruzzese JL. Clinical and prognostic implications of plasma insulin-like growth factor-1 and vascular endothelial growth factor in patients with hepatocellular carcinoma. Journal of clinical oncology : official journal of the American Society of Clinical Oncology. 2011; 29:38923899.

15. Kaseb AO, Xiao L, Hassan MM, Chae YK, Lee JS, Vauthey JN, Krishnan S, Cheung S, Hassabo HM, Aloia T, Conrad C, Curley SA, Vierling JM, Jalal P, Raghav K, Wallace M, et al. Development and validation of insulin-like growth factor-1 score to assess hepatic reserve in hepatocellular carcinoma. Journal of the National Cancer Institute. 2014; 106:1-9.

16. Wiesner R, Edwards E, Freeman R, Harper A, Kim R, Kamath P, Kremers W, Lake J, Howard T, Merion RM, Wolfe RA and Krom R. Model for end-stage liver disease (MELD) and allocation of donor livers. Gastroenterology. 2003; 124:91-96.

17. Hassan MM, Zaghloul AS, El-Serag HB, Soliman O, Patt YZ, Chappell CL, Beasley RP and Hwang LY. The role of hepatitis $\mathrm{C}$ in hepatocellular carcinoma: a case control study among Egyptian patients. Journal of clinical gastroenterology. 2001; 33:123-126.

18. Rahman El-Zayadi A, Abaza H, Shawky S, Mohamed MK, Selim OE and Badran HM. Prevalence and epidemiological features of hepatocellular carcinoma in Egypt-a single center experience. Hepatol Res. 2001; 19:170-179.

19. Shaker MK, Abdella HM, Khalifa MO and El Dorry AK. Epidemiological characteristics of hepatocellular carcinoma in Egypt: a retrospective analysis of 1313 cases. Liver Int. 2013; 33:1601-1606.
20. Zhao L, Feng Y and Xia XS. The different epidemic and evolution of $\mathrm{HCV}$ genotypes. Yi chuan $=$ Hereditas / Zhongguo yi chuan xue hui bian ji. 2012; 34:666-672.

21. Manos MM, Shvachko VA, Murphy RC, Arduino JM and Shire NJ. Distribution of hepatitis C virus genotypes in a diverse US integrated health care population. Journal of medical virology. 2012; 84:1744-1750.

22. Rodriguez-Torres M, Jeffers LJ, Sheikh MY, Rossaro L, Ankoma-Sey V, Hamzeh FM and Martin P. Peginterferon alfa-2a and ribavirin in Latino and non-Latino whites with hepatitis C. N Engl J Med. 2009; 360:257-267.

23. Muir AJ, Bornstein JD and Killenberg PG. Peginterferon alfa- $2 \mathrm{~b}$ and ribavirin for the treatment of chronic hepatitis $\mathrm{C}$ in blacks and non-Hispanic whites. N Engl J Med. 2004; 350:2265-2271.

24. Wantuck JM, Ahmed A and Nguyen MH. Review article: the epidemiology and therapy of chronic hepatitis C genotypes 4, 5 and 6. Alimentary pharmacology \& therapeutics. 2014; 39:137-147.

25. Wali MH, Heydtmann M, Harrison RF, Gunson BK and Mutimer DJ. Outcome of liver transplantation for patients infected by hepatitis C, including those infected by genotype 4. Liver Transpl. 2003; 9:796-804.

26. Zekry A, Whiting P, Crawford DH, Angus PW, Jeffrey GP, Padbury RT, Gane EJ and McCaughan GW. Liver transplantation for $\mathrm{HCV}$-associated liver cirrhosis: predictors of outcomes in a population with significant genotype 3 and 4 distribution. Liver Transpl. 2003; 9:339347.

27. El-Serag HB and Rudolph KL. Hepatocellular carcinoma: epidemiology and molecular carcinogenesis. Gastroenterology. 2007; 132:2557-2576.

28. Llovet JM, Ricci S, Mazzaferro V, Hilgard P, Gane E, Blanc JF, de Oliveira AC, Santoro A, Raoul JL, Forner A, Schwartz M, Porta C, Zeuzem S, Bolondi L, Greten TF, Galle PR, et al. Sorafenib in advanced hepatocellular carcinoma. The New England journal of medicine. 2008; 359:378-390.

29. Cheng AL, Kang YK, Chen Z, Tsao CJ, Qin S, Kim JS, Luo R, Feng J, Ye S, Yang TS, Xu J, Sun Y, Liang H, Liu J, Wang J, Tak WY, et al. Efficacy and safety of sorafenib in patients in the Asia-Pacific region with advanced hepatocellular carcinoma: a phase III randomised, doubleblind, placebo-controlled trial. The lancet oncology. 2009; 10:25-34.

30. The World Bank. Egypt, Arab rep. http://data.worldbank. org/country/egypt-arab-republic. 2013. Accessed December 31, 2014.

31. International Monetary Fund. IMF data mapper: world economic outlook. October 2014. http://www.imf.org/ external/datamapper/index.php. Accessed December 31, 2014.

32. Ibrahim AS, Attia HA, Rabea AM and El-Gayar A. Serum levels of glycosaminoglycans (GAGs) and insulin 
like growth factor-1 (IGF-1) as diagnostic markers for early hepatocellular carcinoma in cirrhotic patients with or without diabetes. Journal of Medical Laboratory and Diagnosis. 2013; 4:8-20.

33. Bruix J and Sherman M. Management of hepatocellular carcinoma. Hepatology (Baltimore, Md). 2005; 42:12081236. 